\title{
Analysis of behavior of adults with Aphasia in a community
}

\author{
Kiyoshi Nosu *
}

Tokai University, Tokyo, Japan

\author{
Key Words: \\ Aphasia \\ Caregiver \\ Computerized communication aid \\ Morphological analysis \\ Questionnaires \\ Utterance
}

Received: 11 March 2017

Accepted: 2 May 2017

Published: 30 June 2017

\begin{abstract}
Aphasia is a disorder involving the disruption of language ability owing to brain injury. Practical communication support tools for adults with aphasia have been proposed, some of which are used in therapy and daily communication. The recent development of specialized applications and information technology, especially tablet computers and other portable devices, can improve communication between adults with aphasia, their caregivers, therapists, and others. The present study aimed to identify the needs of adults with aphasia and caregiving family members concerning communication aids. This paper analyzes the behavior of adults with aphasia in a community to clarify the preliminary requirements of computerized communication aid in Japanese for aphasics and their caregivers. The study data were obtained through (1) responses to questionnaires conducted on aphasics and their caregiving family members and (2) a morphological investigation of aphasics in community-based rehabilitation training. The principal results can be summarized as follows: (i) adults with aphasia and their caregiving family members have difficulty communicating in various situations in their daily lives; among these, the most serious issue is the ability to share the conditions of the adult with aphasia; (ii) the noun utterances of the participants were diverse in terms of the frequency and content of uttered nouns; and (iii) the verbs frequently uttered by the adults with aphasia were limited in number. Based on these findings, the preliminary conceptual design of a computer-based communication support tool is discussed as follows: (a) in addition to language impediments, adults with aphasia are more or less paralyzed; however, portable tablet PCs incorporating communication support software represent a promising communication aid; and (b) since the tendencies of verb and noun utterances differed among the participants, at least two different types of communication software should be implemented on tablet PCs.
\end{abstract}

\section{INTRODUCTION}

Aphasia is a disorder involving the disruption of language ability owing to brain injury that disturbs all language skills, including speaking, hearing, reading and writing $[1,2]$. In most cases, aphasia is caused by stroke; therefore, individuals with aphasia tend to be older adults. It is important for persons with aphasia to pay attention to their activity and participation levels, as opposed to their level of impairment [3]. The purpose of the present study was to identify the needs of adults with aphasia and caregiving family members in terms of communication aids. This paper presents an analysis of the behavior of adults with aphasia in a community to clarify so the preliminary requirements of a computer-based communication aid for aphasics and their caregivers. Section II reviews related literatures of aphasia. Section III describes the research methodology of this pa-

\footnotetext{
${ }^{*}$ Corresponding author: Kiyoshi Nosu

${ }^{\dagger}$ Email: nosukiyoshi@gmail.com
} 
per. Section IV describes the activities of a researched community-based aphasic group, where, in addition to running a rehabilitation program, volunteers and Speech-LanguageHearing Therapists (STs) try to create a communication-friendly environment for adults with aphasia by meeting other aphasics on a regular basis. Section $V$ describes the results of an analysis of responses to the questionnaire survey conducted on aphasics and their caregiving family members.

Section VI describes the results of the utterances of aphasics at meetings from 2012 to 2016. Section VII discusses the preliminary requirements of a computer-based communication aid in Japanese for adults with aphasia in a community and their caregivers. Finally, Section VIII summarizes the obtained research results. The author has been carrying out participative observation in a community-based aphasia support group for more than four years. The study data were obtained through:

(1) Responses to questionnaires conducted on aphasics and their caregiving family members.

(2) A morphological investigation of the utterances of aphasics in community-based rehabilitation training.

Although $[4,5]$ researched the same aphasic group investigated in the present study, the novelty of the present research is as follows:

(1) The questionnaire survey revealed necessary items for communication between adults with aphasia and their caregivers to clarify the requirements of a computer-based communication aid, which are described in Section V.

(2) The study period of the present research is longer than that of the previous two studies; therefore, the present study was able to compare the utterance activities of the first two years to that of the second two years, which is described in Section VI.

(3) The above results reveal conceptual considerations for a computer-based communication aid in Japanese for adults with aphasia and their caregivers, which are described in Section VII.

\section{LITERATURE REVIEW}

Previous studies have examined a variety of perspectives regarding aphasia, including assessments and interventions for rehabilitation $[6,7,8]$ communication training $[9,10,11]$ community support $[12,13,14,15,16,17]$ verb and noun utterances and other languagerelated aspects $[18,19,20,21]$ and computer and communication aids $[22,23,24,25,26]$. Aphasics tend to have reading, writing, listening, and speaking disabilities. If an aphasic has a physical disability in their writing hand, speaking becomes even more important in expressing their will, even though they still tend to have difficulties in articulation, verbal frequency, word-finding, and syntax, among others. The role of computer-based technology for aphasia rehabilitation and communication support is becoming increasingly important.

An assessment of aphasia using an iPad-based application has been carried out in English-speaking countries [22] and the effects of word order on therapy and Japanese comprehension have been investigated $[10,18]$. However, previous research has revealed the limited aspects of communication aids for the Japanese language. To the author's knowledge, there has been no report on the requirements of a computer-based communication aid for adults with aphasia and their caregivers in a Japanese community based on the survey on them as well as the analysis of utterance of the aphasics. 


\section{RESEARCH METHODOLOGY}

This section describes a research procedure for the requirements of a computer-based communication aid for adults with aphasia and their caregivers in a Japanese community. The procedure is as follows:

(1) The activities of a researched community-based aphasic group for Japanese adults with aphasia by meeting other aphasics on a regular basis. (Section IV)

(2) The questionnaire survey conducted on aphasics and their caregiving family members in a Japanese community and the analysis of their responses. (Section V)

(3) The morphological analysis of the utterances of aphasics at monthly meetings in four years. (Section VI)

(4) The discussion on the preliminary requirements of a computer-based communication aid in Japanese for adults with aphasia in a community and their caregivers. (Section VII)

\section{Researched Community-Based Aphasic Group}

The WHO advocates shifting attention in treatment to activity and participation levels as opposed to the level of impairment [27]. In the field of aphasia rehabilitation, this means that concepts such as functional communication and communicative roles are becoming increasingly important for clinicians and researchers, and recent publications have shown an increased focus on activity and participation levels [3]. Some rehabilitation programs and activities for aphasics have been organized under the framework of the International Classification of Functioning Disability and Health (ICF) model proposed by the WHO. The ICF model synthesizes the medical and the social approach to health care for people with chronic diseases in daily life.

The Yokohama Aphasia Partner Group in Yokohama, Japan, is an example of this approach [28]. The participants of the present study were members of the Yokohama Aphasia Partner Group, their families, STs, psychiatric social workers, and volunteers from Yokohama. After the onset of brain hemorrhage and hospital treatment for a certain period, the adults with aphasia returned to living in their communities. At the time of this study, 20 adults with aphasia, most of whom were in their 50s or 60s, were registered as group members. About 10-15 members typically attend each monthly meeting. The monthly meetings include the following four programs:

Program 1: "Warm-up physical exercises and vocal training" conducted by STs,

Program 2: "Individual oral presentations of recent activities" with the support of other members, STs, and volunteers (more time is typically devoted to this program).

Program 3: "Language games for training".

Program 4: "Singing Japanese children's songs together".

It should be noted that at the meetings, some aphasics are assisted by STs or volunteers in giving their presentations.

\section{RESEARCH RESULTS}

\section{Research Results 1, Questinnaires conducted on Aphasics and their Caregiving Familiy Members}

An investigation of members with aphasia and their caregiving family members was carried out using questionnaire surveys sent to all members and their families in 2015 [28]. The questionnaires were completed and returned by 10 of the 20 members, some of whom needed assistance from their family members to complete the surveys. 


\section{Members with aphasia}

The questionnaire survey conducted on aphasics included the following items:

1) Motivational factors for attending the monthly meetings.

2) Effective programs in the monthly meetings.

3) Frequent community activities.

Figures 1, 2, and 3 show the aphasics' motivational factors for attending monthly meetings, effective programs in the monthly meetings, and frequent community activities, respectively. The results indicate that, in addition to medical or biological treatment, aphasics are interested in community-based mutual support, which improves their activity and participation levels in the ICF model.

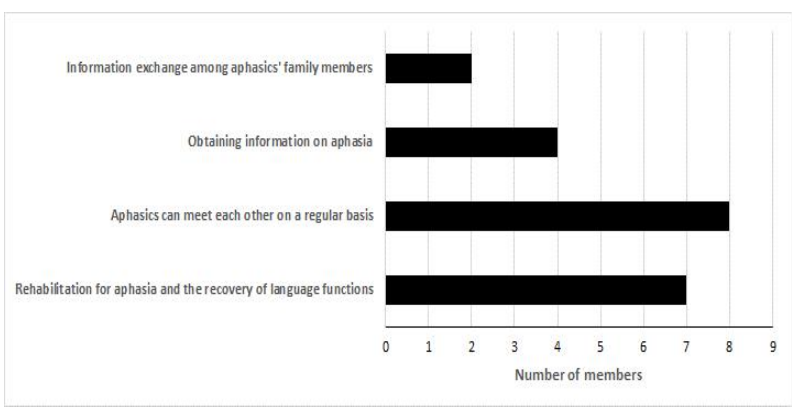

FIGURE 1. Aphasics' motivational factors for attending monthly meetings

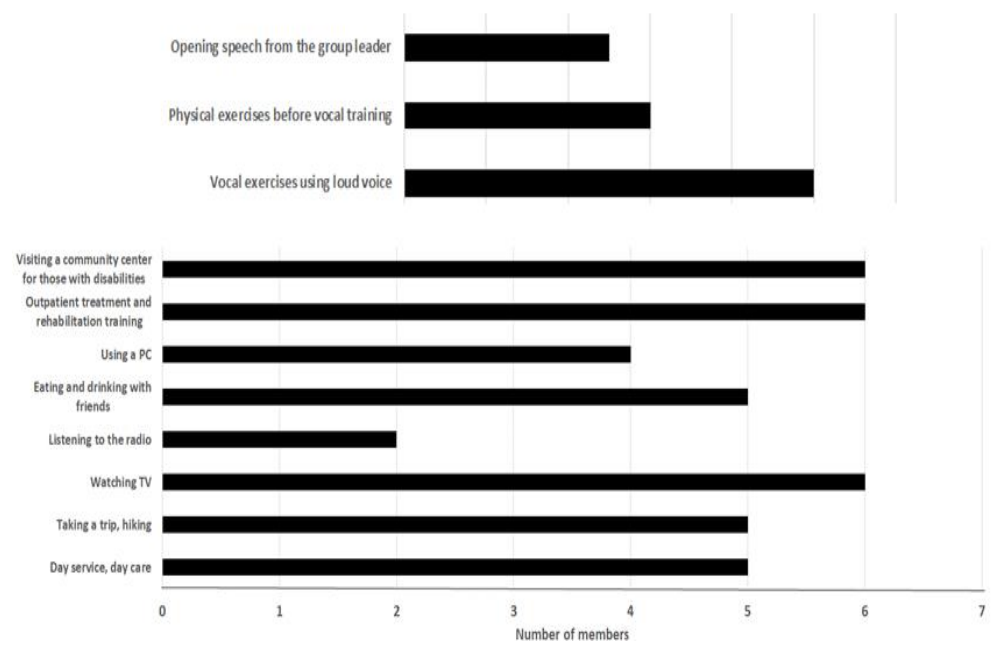

FIGURE 2. Frequent community activities

\section{Aphasics' caregiving family members}

The questionnaire survey conducted on the aphasics' caregiving family members included the following items:

1) Useful messages from a caregiver to an aphasic if portable communication assistance is available.

2) Useful messages from an aphasic to a caregiver if portable communication assistance is available.

3) Caregiving family members' requests to the welfare administration. 
Figures 4, 5, and 6 show the results of the above three items, respectively. The results indicate that portable communication assistance is important because communication between aphasics and their caregiving family members is essential for promoting increased activity levels.

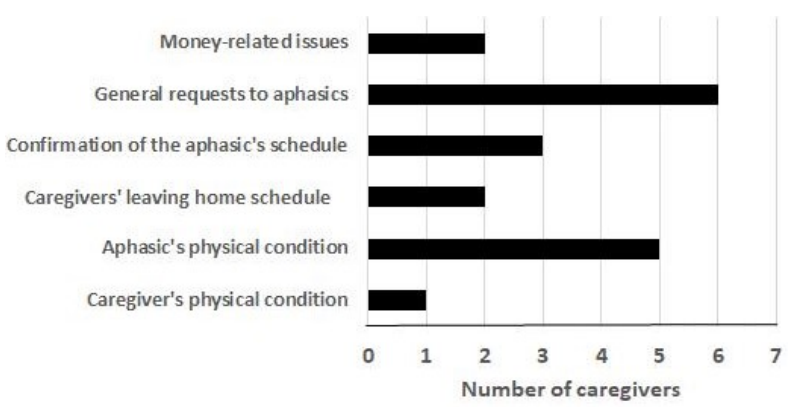

FIGURE 3. Useful messages from caregivers to aphasics through portable communication assistance

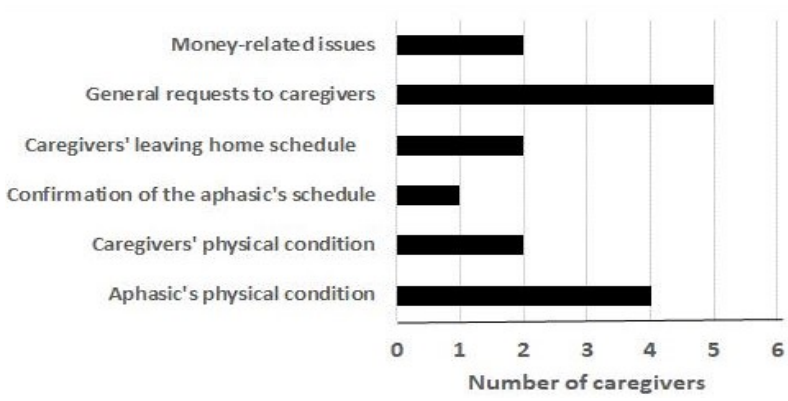

FIGURE 4. Useful messages from aphasics to caregivers through portable communication assistance

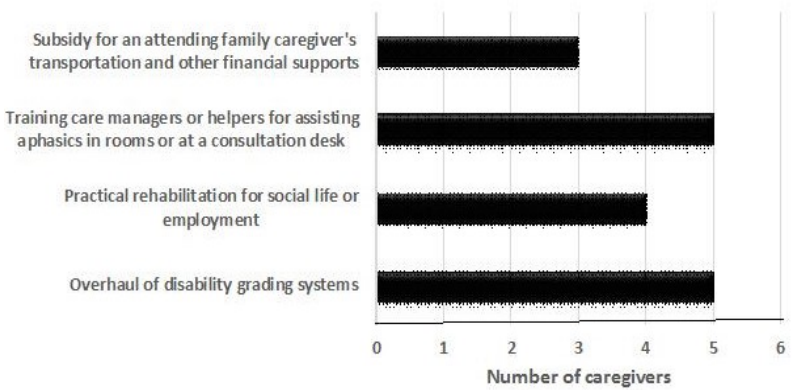

FIGURE 5 . Caregiving family members' requests to the welfare administration

\section{Research Results 2, Morphological Investigation of Aphasics Speech}

The oral presentations of recent activities given by members at monthly meetings were recorded for analysis over a four-year period from June 2012 to May 2016. The members were four males in their 50s and 60s (Members A, B, C, and D). Table 1 summarizes the utterances of the four members. Although all four members were more or less able to understand one another, their fluency levels differed. The four male members tended to the show the symptoms of Broca's aphasia, namely problems in their oral expression ability. 
The measurement and analysis tools employed are as follows:

a) A voice recorder.

b) A PC with Microsoft Word.

c) The following data processing software:

c-1) R (open-source software for statistical analysis)[29].

c-2) MeCab (open-source Japanese language morphological analysis software) [30].

c-3) Microsoft Excel (table calculation software). The analysis procedure was as follows:

A. At monthly meetings

a-1) utterances at monthly meetings were recorded.

a-2) uttered key phases or words were recorded in text files.

B. After monthly meetings

b-1) a complete meeting record draft was composed as a text file.

b-2) another volunteer corrected the meeting record where necessary.

b-3) the meeting record was printed and distributed to the members, STs, and volunteers for confirmation.

b-4) the utterance data of Program 2: "Individual oral presentations of recent activities" of members A, B, C, D were extracted for analysis. *b-5) R open-source software for statis-

TABLE 1. Attributes of the four male

\begin{tabular}{lcccc}
\multicolumn{1}{c}{ members } & & & & \\
\hline \hline Items /Members & A & B & C & D \\
\hline Onset age (years) & 61 & 59 & NA & 59 \\
Current age (years) $\left(^{*}\right)$ & 66 & 64 & NA & 63 \\
Evaluation Hearing & 3 & 3 & 3 & 3 \\
Fluency & 2 & 3 & 1 & 2 \\
Sociality & 1 & 3 & 3 & 2 \\
\hline \hline Notes & & & &
\end{tabular}

NA= not available, but over 60

$\left(^{*}\right)$ Ages in 2015

Evaluation: 1 severly imapried, 2 = some what impaired, 3 = midly impaired, Hearing: ability to understand to understand spoken speech, Fluency: ability to utter and communicate thoughts,

Socially: activities outside the homewith an an acquaintance

tical analysis and $\mathrm{R}$ with MeCab open-source software were used to analyze the utterance data of the four members.

b-6) the analyzed results were stored in an Excel file.

Figure 7 shows the number of talks given in Periods I and II, with Period I covering June 2012 to May 2014, and Period II covering June 2016 to May 2016. The number of talks increased from Period I to Period II. This might have been because the members became increasingly used to their living environments, and/or because the STs and volunteers gained a better understanding of the members' individual characteristics. Although Member A showed a passive attitude toward communication, he still responded to the inquiries from other members. Members B and C talked spontaneously. Member D's attitude was considered as being between Member A and Members B and C. 


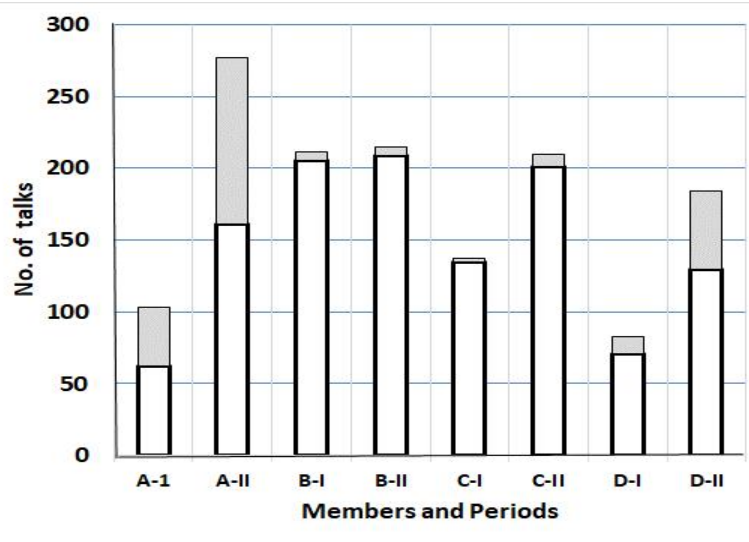

$\square$ No. of subjects' talks $\square$ No. of other members' talks

FIGURE 6. Number of talks in Periods I and II

Period I: June 2012 to May 2014

Period II: June 2016 to May 2016

\section{Morphological investigation of nouns}

Table 2 shows the results of the noun analysis, including the number of extracted nouns and the number of different nouns (as opposed to the total number of uttered nouns). Figure 8 shows the number of nouns uttered in Periods I and II, with Period I covering June 2012 to May 2014, and Period II covering June 2016 to May 2016. Since aphasics have limited speaking ability, simple word categorization was introduced; namely, nouns were grouped into "common nouns" and "proper nouns". The results suggest that the utterances of the four members were diverse in terms of the frequency and content of their uttered nouns. These differences might reflect their own disabilities and living environments.

TABLE 2. Summary of uttered nouns

\begin{tabular}{|c|c|c|c|c|c|c|c|c|}
\hline Items & $\mathbf{A}$ & & B & & $\mathrm{C}$ & & D & \\
\hline Numbers of attended meetings & 34 & & 44 & & 36 & & 33 & \\
\hline Numbers of extracted nouns & 259 & & 1546 & & 774 & & 369 & \\
\hline Numbers of different nouns & 181 & & 685 & & 409 & & 202 & \\
\hline Numbers of Nouns $>1 \%$ & 17 & & 5 & & 9 & & 18 & \\
\hline & Nouns & Ty-Fr-Rat- & Nouns & Ty-Fr-Rat- & Nouns & Ty-Fr-Rat- & Nouns & Ty-Fr-Rat- \\
\hline & Mountain & C-8-0.03 & Baseball & C-32-0.02 & Meeting & $C-16-0.02$ & Today & C-17-0.05 \\
\hline & Elder sister & C-8-0.03 & Japan & P-22-0.02 & Rapport & P-13-0.02 & Grandchild & C-14-0.04 \\
\hline & Television & C-6-0.02 & Championship & C-20-0.01 & Alcholic & C-12-0.02 & Home & C-9-0.02 \\
\hline & News & C-6-0.02 & High School & C-19-0.01 & Beer & C-11-0.01 & Daughter & C-9-0.02 \\
\hline & Bus & C-5- 0.02 & Final game & C-14-0.01 & Yokohama & P-12-0.02 & Age & C-8-0.02 \\
\hline & Home & C-5-0.02 & & & Shin-Yokohama & P-12-0.02 & Boy & C-8-0.02 \\
\hline & Talk & C-5-0.02 & & & Year & C- $10-0.01$ & Thing & C-7-0.02 \\
\hline & Ireland & P-4-0.02 & & & Number of times & C-10-0.05 & Frquency & C-7-0.02 \\
\hline & Gumyoji & P-4-0.02 & & & Friend & C-9-0.01 & Girl & C-7-0.02 \\
\hline & Station & C-3-0.01 & & & & & Young age & C-5- 0.01 \\
\hline & Foreign Contries & C-3-0.01 & & & & & Architect & C-5-0.01 \\
\hline & Now & C-3-0.01 & & & & & Examination & C-5-0.01 \\
\hline & Walk & C-3-0.01 & & & & & Time & C-5-0.01 \\
\hline & Zushi & P-3-0.01 & & & & & Older age & C-5-0.01 \\
\hline & Sumo & C-4-0.02 & & & & & Name & C-5- -0.01 \\
\hline & Train & C-3-0.01 & & & & & First Thing & C- $4-0.01$ \\
\hline & Friend & C-3-0.01 & & & & & House hold & C- $4-0.01$ \\
\hline & & & & & & & Plan & C- $4-0.01$ \\
\hline
\end{tabular}

\section{notes}

Ty = noun type, $\mathrm{C}$ : common noun, $\mathrm{P}$ : proper noun

$\mathrm{Fr}=$ utterance frequancy

Rat $=$ utterance ratio 


\section{Morphological investigation of verbs}

Table 3 shows the results of the verb analysis, including the number of extracted verbs, the number of different verbs (as opposed to the total number of uttered verbs), and the frequency of uttered verbs (higher than 1\%). Since aphasics have limited speaking ability, verbs were roughly classified into those that express either "states" or "actions". The results also show that five verbs ("go", "stay", "exit", "come", and "carry out") were frequently uttered by all four members, and three verbs ("see" or "watch", "become", and "walk") were frequently uttered by three members. Figure 8 shows the total number of verbs and different verbs in Periods I and II, with Period I covering June 2012 to May 2014, and Period II covering June 2016 to May 2016. It shows that the number of different verbs among the four members was almost the same in Periods I and II.

TABLE 3. Summary of uttered nouns

\begin{tabular}{|c|c|c|c|c|c|c|c|c|}
\hline Items & $\overline{\mathbf{A}}$ & & B & & 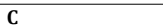 & & 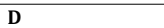 & \\
\hline Numbers of attended meetings & 34 & & 44 & & 36 & & 33 & \\
\hline Numbers of extracted verbs & 164 & & 384 & & 307 & & 158 & \\
\hline Numbers of different verbs & 13 & & 16 & & 14 & & 24 & \\
\hline \multirow[t]{20}{*}{ Numbers of verbs $>1 \%$} & 13 & & 16 & & 14 & & 24 & \\
\hline & Verb & Ty-Fr-Rat- & Verb & Ty-Fr-Rat- & Verb & Ty-Fr-Rat- & Verb & Ty-Fr-Rat- \\
\hline & Go (4) & A-39-0.238 & Stay (4) & S-78-0.203 & Go (4) & A-112-0.365 & Stay (4) & S-41-0.259 \\
\hline & Stay (4) & S-25-0.152 & Do something (4) & A-68-0.0177 & Do something (4) & A-43-0.14 & Exist (4) & S-17-0.108 \\
\hline & Exist (4) & A-21-0.128 & Become (3) & S-48-0.125 & Stay (4) & S-36-0.117 & Come (4) & A-19-0.12 \\
\hline & See or watch (4) & A-19-0.116 & Exist (4) & S-39-0.102 & Drink & A-27-0.088 & Do something (4) & A-14-0.089 \\
\hline & Do something (4) & A-15-0.091 & Go(4) & A-38-0.099 & Exist (4) & S-18-0.059 & Speak & A-7-0.044 \\
\hline & Speak & A-10-0.061 & Think & A-25-0.065 & See or watch (4) & A-15-0.049 & Go (4) & A-8- 0.051 \\
\hline & Walk (3) & A-9-0.0.55 & See or watch & A-13-0.034 & Come (4) & A-15-0.049 & Pass & A-5-0.032 \\
\hline & Eat & A-7-0.043 & Begine & A-13-0.034 & Caryy out (3) & A-8-0.026 & Be injected & A-5- 0.032 \\
\hline & Come (4) & A-5-0.03 & Walk (3) & A-11-0.029 & Become (3) & S-7-0.023 & Become (3) & S-4-0.025 \\
\hline & Hear & A-5-0.03 & Finish & A-9- 0.023 & Get together & A- $6-0.02$ & Be born & S-4-0.025 \\
\hline & Climb & A-4-0.024 & Play Sports & A-8-0.021 & Walk & A-6-0.02 & Give something & A-3-0.019 \\
\hline & Go out & A-3-0.018 & Carry out & A-8-0.021 & Go back & A-6-0.02 & Perform & A-3-0.019 \\
\hline & Live & S-2-0.012 & Be done & A-7-0.018 & Sing & A-4-0.013 & Carry out & A-3-0.019 \\
\hline & & & Win & A-7-0.018 & Get down & A-4-0.013 & Think & A-3-0.019 \\
\hline & & & Come (4) & A-6- 0.016 & & & Live & S-3-0.019 \\
\hline & & & Be settled & A-6- 0.016 & & & Time goes by & $\mathrm{A}-2-0.013$ \\
\hline & & & & & & & Receive & A-2-0.013 \\
\hline & & & & & & & Getup & A-2-0.013 \\
\hline
\end{tabular}

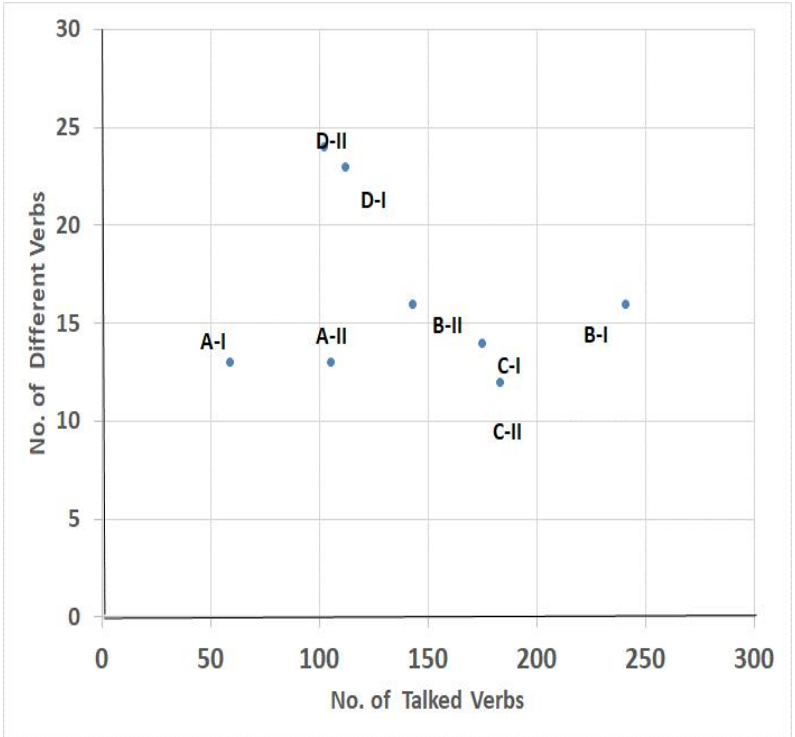

FIGURE 7. Number of uttered verbs in Periods I and II

Period I: June 2012 to May 2014

Period II: June 2016 to May 2016 


\section{DISCUSSION ON PRELIMINARY CONCEPTUAL DESIGN OF COMPUTER-BASED COM- MUNICATION SUPPORT}

Section $\mathrm{V}$ described the results of an analysis of responses to the questionnaire survey conducted on aphasics and their caregiving family members. Section VI discussed the morphological analysis of the utterances of aphasics. There have been some reports on Japanese adults with aphasia in connection with therapy and Japanese language comprehension $[10,18]$. However, previous research has discussed the limited aspects of communication aids for the Japanese language. This Section discusses the preliminary requirements of a computer-based communication aid in Japanese for adults with aphasia in a community and their caregivers. The principal results of Sections V and VI are summarized as follows:

(i) adults with aphasia and their caregiving family members have difficulty communicating in various situations in their daily lives. Among these, the most serious issue is sharing the conditions of the adult with aphasia.

(ii) the noun utterances of the subjects were diversified in terms of their frequency and content.

(iii) the verbs frequently uttered by the adults with aphasia were limited in number.

Based on these findings, the preliminary conceptual design of a computer-based communication support tool for adults with aphasia, especially Broca's aphasia, is discussed. The following three characteristic points of Broca's aphasia should be considered:

(1) individuals with Broca's aphasia find speaking fluently substantially more difficult than hearing or comprehension.

(2) phonograms (katakana and hiragana in Japanese) are more difficult to understand than ideograms (Kanji in Japanese), whose forms originated from actual figures. Moreover, it is easier for adults with aphasia to recognize pictograms and pictures than Kanji.

(3) aphasia in most adults is due to stroke, including cerebral thrombosis, infarction, and subarachnoid hemorrhage. Therefore, in addition to language impediments, adults with aphasia are more or less paralyzed. As shown in Table 1, the age of onset was over 50 years for all four members. They were frequently paralyzed on the right side of their bodies, which often causes difficulties in writing for right-handers.

Considering the above characteristic points regarding Broca's aphasia, the principal usage requirements for communication aids are as follows:

(1) communication participants: aphasics and their caregivers.

(2) caregivers: aged persons who are not skilled at using computers and components such as keyboards; voice recognition software is preferable as an input device.

(3) aphasics: visual symbols and illustration-based input devices.

Portable tablet PCs with communication support software are promising candidates as a communication aid. Such devices have the following requirements:

(A) base computer: a tablet PC with a touch panel, microphone.

(B) computer-human interface for aphasics: a touch panel that enables aphasics to draw figures, write characters, and use other visual communication aids.

(C) computer-human interface for caregivers: a microphone that can produce speech output.

(D) processed contents: voice, words, maps, graphics, and other visual aids.

Since the verbs and noun utterance tendencies differed among the investigated members, at least two different communication-support functions should be implemented in a tablet PC. The following iPad applications potentially meet these requirements.

(a) Talking aid - symbol input version (U-PLUS, Japan) 
(b) SpeechCanvas (FEAT, Japan)

(c) Digital map (supplemental software)

"Talking aid - symbol input version" (U-PLUS, n.d.) was developed for persons who have difficulty in verbal communication. A user selects small illustrations shown on a touch panel that represent verbs or nouns. A selected word sequence is shown on the display. It is also converted to a synthesized voice so that a person without disabilities can understand them in a multimodal way. "SpeechCanvas" [31,32,33] was initially developed as a communication aid between deaf and mute individuals and those without disabilities. It converts the voices of people without disabilities to letters that deaf and mute individuals can understand by looking at the display. In addition, deaf and mute individuals can draw figures or write characters on the touch panel using their fingers to communicate with others. "Digital map" is a touch display application that can be freely expanded and reduced.

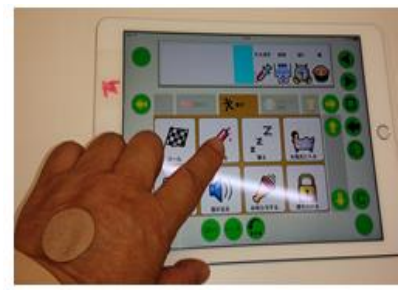

(a)

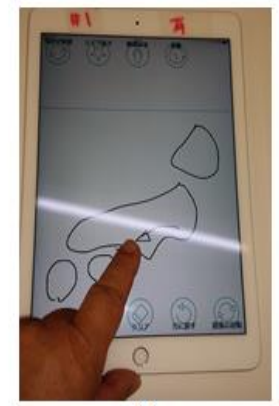

(b)

FIGURE 8. Left hand fingers touching to tablet PC screens. (a)Taking aid-symbol input version, (b)SpeechCanvas

Since the functions of these applications are limited and they compensated each other, the adults with aphasia should select an application in accordance to what kind of a message they want to express. Figure 8 (a) and (b) show left hand fingers touching to tablet PC screens of "Talking aid - symbol input version" and "SpeechCanvas" so that the adults with aphasia effectively express their messages non-verbally respectively. Figure 9 shows a schematic illustration of communication between an aphasic and a caregiver based on the above design considerations.

\section{CONCLUSION}

This study aimed to describe an analysis of the behavior of adults with aphasia in a community. The following data were analyzed:

(1) the responses to questionnaires conducted on aphasics and their caregiving family members.

(2) a morphological investigation of the utterance of Broca's aphasics in community-based rehabilitation training. 
Based on the results, a preliminary conceptual design for a computer-based communication support tool was discussed. The obtained research results are summarized as follows: (1) aphasics are interested in community-based mutual support, which, in addition to medical or biological treatment, improves their social environment and other contextual life factors of the ICF model.

(2) portable communication assistance could potentially be useful because communication between aphasics and their caregiving family members is essential for promoting increased activity levels.

(3) a preliminary conceptual design for a computer-based communication aid for Broca's aphasics and their caregivers was proposed. An iPad with an application that supports communication for those with disabilities was found to be a potential candidate.

The noun utterances investigated in the present study were diverse in terms of frequency and content. A computer-based communication aid system can be easily and dynamically adapted to personal needs. The proposed system provides the following three possible ways:

(i) drawing pictures or writing characters on a touch panel display using the fingers.

(ii) selecting small illustrations on a touch panel and converting them to a synthesized voice so that a person without disabilities can understand them in a multimodal way.

(iii) "Digital map" can show a location freely by expanding and reducing the area of the touch panel. Furthermore, the uttered verbs were not as diverse as the uttered nouns. Therefore, (i) and/or (ii) above might be more convenient.

In a future study, we plan to conduct further investigations to confirm the effectiveness of a computer-based communication aid. Such investigations could include:

(a) field tests of communication between adults with Broca's aphasia, who have difficulties with oral expression, and caregiving family members to clarify the usability of the communication aid.

(b) an investigation involving adults with Wernicke's Aphasia, who have serious difficulties with comprehension.

(c) the application of a computer-based communication aid to those with other disabilities who have difficulties in communication.

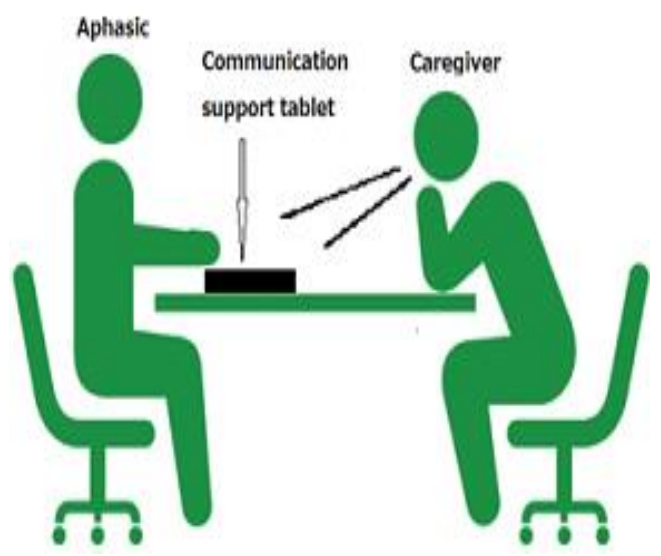

FIGURE 9. Schematic illustration of communication between an aphasic and a caregiver

(d) an investigation in regard to artificial intelligence and novel human interface technologies such as brain-computer and other augmentative interfaces $[25,26]$. 


\section{ACKNOWLEDGMENT}

The author would like to express his sincere thanks to the members of the Yokohama Aphasia Partner Group, their families, STs, and volunteers, especially the four members who agreed to provide the data for analysis.

\section{REFERENCES}

1. Kaplan E. The assessment of aphasia and related disorders. Philadelphia, PA: Lippincott Williams \& Wilkins; 1983.

2. National Aphasia Association. Aphasia definitions; 2014. Available from: goo.gl/bDQ5fc

3. World Health Organization. International classification of functioning, disability and health (ICF) framework to facilitate Interprofessional education and collaborative practice; 2015. Available from: goo.gl/YoWiD9

4. Nosu K, Shigeta A. Analysis of activities of adults with aphasia at community-based rehabilitation training. Journal of Biosciences and Medicines. 2015; 3(12): 7-11. D0I: 10.4236/jbm.2015.312002

5. Nosu K. Analysis of nouns and verbs uttered by adults with aphasia at community-based rehabilitation training. IEEJ Transactions on Electrical and Electronic Engineering. 2016; 11(5): 676-678. D0I: 10.1002/tee.22288

6. Meinzer M, Rodriguez AD, Rothi LJ. First decade of research on constrained-induced treatment approaches for aphasia rehabilitation. Archives of Physical Medicine and Rehabilitation. 2012; 93(1): 35-45. D0I: 10.1016/j.apmr.2011.06.040

7. Saur D, Hartwigsen G. Neurobiology of language recovery after stroke: lessons from neuroimaging studies. Archives of Physical Medicine and Rehabilitation. 2012; 93(1): 15-25. DOI: 10.1016/j.apmr.2011.03.036

8. Choe YK, Foster T, Asselin A, LeVander M, Baird J. Cognitive-linguistic effort in multidisciplinary stroke rehabilitation: Decreasing vs increasing cues for word retrieval. Neuropsychological Rehabilitation. 2017; 27(3): 318-348.

DOI: $10.1080 / 09602011.2015 .1078820$

9. Jensen LR, Løvholt AP, Sørensen IR, Blüdnikow AM, Iversen HK, Hougaard A, Mathiesen LL, Forchhammer HB. Implementation of supported conversation for communication between nursing staff and in-hospital patients with aphasia. Aphasiology. 2015; 29(1): 57-80. DOI: 10.1080/02687038.2014.955708

10. Takizawa T, Nishida N, Ikemoto A, Kurauchi N. Comparison of single-word therapy versus sentence therapy for verb retrieval and sentence production in Broca's aphasia. Aphasiology. 2015; 29(2): 169-194.

DOI: $10.1080 / 02687038.2014 .961121$

11. Wallace SJ, Worrall L, Rose T, Le Dorze G. Which treatment outcomes are most important to aphasia clinicians and managers? An international e-Delphi consensus study. Aphasiology. 2017; 31(6): 643-673.

DOI: $10.1080 / 02687038.2016 .1186265$

12. Aftonomos LB, Appelbaum JS, Steele RD. Improving outcomes for persons with aphasia in advanced community-based treatment programs. Stroke. 1999; 30(7): 1370-1379. DOI: 10.1161/01.str.30.7.1370

13. Howe TJ, Worrall LE, Hickson LM. Interviews with people with aphasia: Environmental factors that influence their community participation. Aphasiology. 2008; 22(10): 1092-1120. DOI: 10.1080/02687030701640941

14. Lanyon LE, Rose ML, Worrall L. The efficacy of outpatient and community-based aphasia group interventions: A systematic review. International Journal of Speech-Language Pathology. 2013; 15(4): 359-374.

DOI: $10.3109 / 17549507.2012 .752865$

15. Tarrant M, Warmoth K, Code C, Dean S, Goodwin VA, Stein K, Sugavanam T. Creating psychological connections between intervention recipients: Development and focus group evaluation of a group singing session for people with aphasia. BMJ Open. 2016; 6(2): 52-96. DOI: 10.1136/bmjopen-2015-009652

16. Wallace SJ, Worrall L, Rose T, Le Dorze G, Cruice M, Isaksen J, Kong AP, Simmons-Mackie N, Scarinci N, Gauvreau CA. Which outcomes are most important to people with aphasia and their families? An international nominal group technique study framed within the ICF. Disability and Rehabilitation. 2017; 39(14): 1364-1379. DOI: 10.1080/09638288.2016.1194899 
17. Cruice M, Hill R, Worrall L, Hickson L. Conceptualising quality of life for older people with aphasia. Aphasiology. 2010; 24(3): 327-347. DOI: /10.1080/02687030802565849

18. Kinno R, Kii Y, Kurokawa S, Owan Y, Kasai H, Ono K. Effects of word order and morphological information on Japanese sentence comprehension in nonfluent/agrammatic variant of primary progressive aphasia. Journal of Neurolinguistics. 2017; 44(2): 107-119. DOI: org/10.1016/j.jneuroling.2017.03.006

19. Kambanaros M. Verb and noun word retrieval in bilingual aphasia: A case study of language-and modality-specific levels of breakdown. International Journal of Bilingual Education and Bilingualism. 2016; 19(2): 169-184.

DOI: $10.1080 / 13670050.2015 .1037717$

20. Caramazza A, Hillis AE. Lexical organization of nouns and verbs in the brain. Nature. 1991; 349(6312): 788-799. DOI: $10.1038 / 349788 \mathrm{a} 0$

21. Waon NPO. Let's talk to people with aphasia. Tokyo, JA: Chuohouki, 2012.

22. Guo YE, Togher L, Power E, Hutomo E, Yang YF, Tay A, Yen SC, Koh GC. Assessment of Aphasia across the international classification of functioning, disability and health using an iPad-based application. Telemedicine and E-Health. 2017; 23(4): 313-326. DOI: $10.1089 /$ tmj.2016.0072

23. Van de Sandt-Koenderman WM. Aphasia rehabilitation and the role of computer technology: Can we keep up with modern times? International Journal of Speech-Language Pathology. 2011; 13(1): 21-27.

DOI: $10.3109 / 17549507.2010 .502973$

24. Kane SK, Linam-Church B, Althoff K, McCall D. What we talk about: Designing a context-aware communication tool for people with aphasia. Paper presented in Proceedings of the 14th international ACM Sigaccess conference on Computers and Accessibility 2012, October 22, Boulder, CO.

25. Kleih SC, Gottschalt L, Teichlein E, Weilbach FX. Toward a P300 based brain-computer interface for Aphasia rehabilitation after stroke: Presentation of theoretical considerations and a pilot feasibility study. Frontiers in Human Neuroscience. 2016; 10(3): 34-47. DOI: 10.3389/fnhum.2016.00547

26. Kusoom W. Health behaviors and health risk behaviors among vocational students: Case study of vocational college in Nakornratchasima province Thailand. Journal of Advances in Health and Medical Sciences. 2016; 2(3): 96-102.

27. Russo MJ, Prodan V, Meda NN, Carcavallo L, Muracioli A, Sabe L, Bonamico L, Allegri RF, Olmos L. High-technology augmentative communication for adults with post-stroke aphasia: A systematic review. Expert Review of Medical Devices. 2017; 14(5): 355-370. DOI: 10.1080/17434440.2017.1324291

28. World Health Organization. Disability and health; 2016. Available from: goo.gl/cjQ65F

29. Yokohama Shitsugosho Tomono-kai. Monthly meeting report; 2016. Available from: goo.gl/UenEuy

30. CRAN. The comprehensive archive network; 2017. Available from: goo.gl/5shtr3

31. Me Cab. Morphological analyzer; 2014. Available from: goo.gl/PsoV58

32. FEAT. Speech canvas; 2013. Available from: goo.gl/1KwzBN

33. Goyal B, Goyal RC. Community thinking and acting: An evaluation of effectiveness of health talks, health exhibitions, role plays and puppet shows. International Journal of Health and Medical Sciences 2015; 1(3): 65-69. 